\title{
EL TIEMPO EN TUS MANOS. ANAMNESIS EN MOVIMIENTO
}

\section{The world in your arms. Anamnesis moving}

\author{
Josep M. Català Domènech*
}

\begin{abstract}
RESUMEN
El imaginario de la historiografía aún no se ha acomodado a las nuevas formas de entender el tiempo que se desprenden tanto de la invención del cine como de las propuestas que Einstein y Minkowski desarrollaron poco después en el campo de la física, especialmente la de una realidad espacio-temporal. Pero estos planteamientos deben ampliarse además con la perspectiva de una dimensión de carácter real-imaginario que a las cuatro dimensiones tradicionales añade la visualización que, a través del movimiento, proponen las formas cinemáticas. Esta visualización convierte el espacio-tiempo en un dispositivo hermenéutico con el que pensar la realidad.
\end{abstract}

Palabras clave: movimiento, espacio-tiempo, pensamiento visual.

\begin{abstract}
The imaginary of historiography has not yet accommodated to the new ways to understand time that emerged both from the invention of cinema and from the proposals that Einstein and Minkowski developed shortly after in the field of physics, especially what concerns the reality of space-time. But these approaches should be extended further with the prospect of another dimension of a real-imaginary nature that should be added to the traditional four-dimensional reality. This new dimension comes from the visualization of space-time that, through movement, proposed the cinematic forms. This display of the space-time becomes a hermeneutical device with whom it is possible to think about reality.

Keywords: movement, space-time, visual thinking.
\end{abstract}

\footnotetext{
“Catedrático de la Universitat Autònoma de Barcelona. josepmaria.catala@uab.cat
} 
Arde en las cosas un terror antiguo,

Un profundo y secreto soplo

Enrique Molina

Quería dibujar la conciencia del existir

$y$ del flujo del tiempo

Henri Michaux

\section{Nunca hemos sido modernos}

En un principio fue el movimiento. Es con el movimiento que nace no tanto el mundo moderno como el posmoderno. Es decir que es con el movimiento con el que la modernidad traspasa sus propias fronteras y se escapa hacia otra parte que denominamos posmoderna. Lo cual quiere decir que, como indicaba Latour, nunca fuimos modernos porque, nada más empezar, la modernidad alcanzó una velocidad de escape hacia otra parte a la que, en realidad, todavía no hemos llegado.

Desde que Benjamin señaló la fotografía como el inicio de un período nuevo en el arte y la representación, nos hemos quedado inmovilizados ante esta idea, hemos fijado nuestra mirada en la fotografía y desde esa posición hemos edificado el mundo moderno, su imaginario, un edificio levantado sobre una sólida base pero un edificio inmóvil al fin y al cabo, como corresponde a los bienes inmuebles, un edificio destinado a durar eternamente. Es decir, una paradoja, puesto que ese edificio destinado a durar eternamente, en realidad no conseguía sobrevivir ni a su propia inauguración. Al tiempo que Joseph Nicéphore Niépce inventaba la fotografía a partir de las ideas de Thomas Wedgwood, que fue el primero que realmente pensó en inmovilizar el tiempo a través de sus imágenes, ya todo se confabulaba para que estas imágenes permanentes, imágenes inmóviles equiparables a la supuesta inmovilidad del recuerdo, se pusieran en movimiento a través multitud de artilugios distintos.

La fotografía supuso la última actuación de un mundo basado en la metafísica de la inmovilidad, pero no fue hasta la llegada del cine que la imagen, y con ella el mundo, empezó a perder consistencia. Con la fotografía se eliminaba a la vez el espacio y el tiempo, pero simultáneamente 
se ponían las bases para que apareciera el nuevo e impensable fenómeno del espacio-tiempo. El espacio-tiempo es el resultado de la combinación tecnológica de los fantasmas del espacio y el tiempo desaparecidos, el cuerpo de los cuales regresa desmaterializado a través, principalmente, de la técnica cinematográfica.

La fotografía eliminaba el espacio de la representación porque lo cubría totalmente con una imagen producida automáticamente. Mientras que la pintura se ejecutaba sobre una superficie en principio vacía que el pintor debía llenar con los productos de su imaginación o con la copia de la realidad: en la fotografía no hay un espacio previo, sino que este se confunde con la imagen que sustenta, ambos forman una unidad indisoluble. La pintura, como nos recuerda Deleuze ${ }^{1}$, no siempre obraba a través de un espacio vacío, puesto que, antes de que el pintor empezara su trabajo, ya existía lo que este filósofo denomina el "cliché", que era como una plantilla que organizaba el espacio antes de que se empezara a llenar con la imagen pictórica: el espacio estaba ya conformado de antemano antes de que el pintor lo trabajara. El hecho de que, desde el Renacimiento, se equiparara la pintura con una ventana, implica una tendencia a borrar el espacio como lugar de trabajo abierto. La fotografía no hace sino culminar esa tendencia con un gesto técnico que parece definitivo. El espacio soporte con ella desaparece y el "cliché" es resultado de la operación fotográfica: se convierte en el molde desde el que la foto esencial se diseminará en una multitud posible de copias. De ahí que la culminación de la estabilidad esencial coincida con el inicio de la diseminación no menos básica.

Que la fotografía tiende también a suprimir el tiempo, puede que sea algo ya más sabido, aunque quizá la idea no se haya orientado adecuadamente. El hecho de que la fotografía inmoviliza el fluir temporal no es una novedad, como tampoco lo es que preserva los recuerdos. Esta función maravillosa y sorprendente que permite congelar el presente y convertirlo de inmediato en memoria visual encandiló a una fase de la modernidad empeñada en convertir el mundo en un cúmulo de hechos pesables y medibles y, por lo tanto, archivables. Por esta senda, la fotografía se relacionaba con la historia y, como sea que la historia era la ciencia del tiempo por antonomasia, la alianza parecía perfecta puesto que ambas se daban la razón la una a la

2008.

1 DELEUZE, Gilles. Pintura. El concepto de diagrama. Buenos Aires: Editorial Cactus, 
otra. La historia positivista, que pretende convertir el tiempo pasado en una colección de hechos converge con una técnica fotográfica capaz de fijar el presente y transformarlo aparentemente en un hecho tan sólido como esa historia querría que fueran todos los hechos. Se trata de una idea que estaría en la base de la metafísica de la modernidad, que como hemos dicho está poseída por la idea mesiánica del final de los tiempos.

La concepción kantiana del espacio y el tiempo es sumamente limitada. Kant considera que el espacio y el tiempo son formas puras de nuestra sensibilidad: el espacio gestiona nuestra sensibilidad externa, mientras que el tiempo lo hace con nuestra sensibilidad interna. Pero como todas las intuiciones pasan por nuestro espíritu, es el tiempo el que las organiza, de ahí una prioridad de la sensibilidad temporal sobre la espacial: esta se ve siempre organizada por aquella. Tiempo y espacio son condiciones de lo posible y, por lo tanto, están más allá de la realidad ya que sin esas formas de nuestra sensibilidad no habría realidad posible. Pero Kant no contaba con la capacidad futura de la tecnología para reproducir esas sensibilidades esenciales, para externalizar las condiciones apriorísticas de la experiencia y, en consecuencia, del pensamiento. Aparte del escaso interés que la estética, como disciplina filosófica, mostraba por las características fenomenológicas de los medios, la experiencia pictórica, como he dicho, tendía a presentarse como una prolongación mimética de la realidad y no como una plataforma para pensarla. De ahí que no se desarrollara un pensamiento adecuado del espacio hasta finales del siglo XIX y principios del XX. Y en cuanto al tiempo, era aún más difícil que se intuyera la posibilidad de una externalización del mismo que propusiera una plataforma impulsora del pensamiento. Lo cierto es que una perspectiva como ésta aún ahora sigue siendo problemática.

\section{Visiones del tiempo}

La disciplina histórica se ha ocupado muy poco de los problemas del tiempo, quizá porque da el tiempo por sentado. Al considerar que es su materia prima, supone que lo tiene bajo control, cuando lo cierto es que el tiempo en sí se escapa constantemente por los resquicios de su metodología, basada en una sensibilidad que, aunque parezca paradójico, es ajena a la 
fenomenología del tiempo. Sin embargo, lo cierto es que no se trata de una acusación tan grave, si tenemos en cuenta que, en el mundo de la cultura, solo los físicos y algunos escritores de ciencia ficción se han ocupado verdaderamente de este tipo de problemas.

Estudiar el pasado no es estudiar el tiempo, sino el contenido del tiempo o, dicho de otra forma, más precisa: la historia utiliza una determinada idea del tiempo para organizar los sucesos del pasado según la cual este es como un recipiente en el que se van colocando los contenidos -o del que, según como se mire, se van extrayendo -, sin que se preste ninguna atención a la forma del mismo, asumiendo que el receptáculo nada tiene que ver con lo que se sitúa en su interior y que además su morfología es uniforme e inmutable. Sin embargo, no solo en los sucesos que van a parar a ese interior, que surgen del mismo, laten muy diversas formas temporales, sino que además estas se modifican dependiendo de cómo y dónde se colocan, de lo que se deduce finalmente que no existe ese recipiente ideal dispuesto a recibir o a arropar el contenido de la historia, sino que la morfología temporal surge de la disposición específica de estos contenidos, del conglomerado de tiempos que constituyen. En resumidas cuentas: el tiempo es, entre otras muchas cosas, una construcción. Pero para comprender el alcance de todo ello hay que tener en cuenta que estos problemas tienen que ver con una nueva dimensión del tiempo apenas detectada y que corresponde a una fase en que el mismo está siendo visualizado. Por consiguiente, estos fenómenos no pueden comprenderse ni tomarse en consideración hasta no saber qué relaciones establece el tiempo con la visualidad, es decir, con el paradigma de la imagen.

Para empezar, es necesario ponerse de acuerdo en qué es exactamente el tiempo, un problema que quizá sea insoluble si se siguen haciendo tan solo preguntas de carácter primordialmente filosófico, cuando lo que se requiere también son preguntas y respuestas pragmáticas. Creo que es mucho más productivo preguntarse ¿qué cosas hacemos con el tiempo? que no pretender indagar qué es el tiempo en abstracto, porque quizá el tiempo en abstracto no sea nada en absoluto. Su esencia, o sus diversas esencias posibles, están más relacionadas con el uso que hagamos del fenómeno que no con la concepción que del mismo se pueda tener. O mejor dicho, la esencia del tiempo se concibe y percibe mucho mejor si la extraemos de sus diversas utilizaciones. 
Puede que nos aclaren esta cuestión las metáforas que K. M. Jaszczolt emplea para explicar las dos principales modalidades temporales $^{2}$. El tiempo, nos dice, se puede pensar, en primer lugar, acudiendo a la imagen del teleférico de una estación de esquí: la línea está constantemente en movimiento en una dirección y a las sillas se van incorporando los esquiadores para subir a la montaña. La otra imagen que propone Jaszczolt implica concebir el tiempo como una cuerda de tender la ropa: en este caso se trata de una línea inmóvil a la que se le van incorporando las piezas de ropa, unas a continuación de las otras. Así como en el primer caso el tiempo se mueve, fluye desde el pasado al presente y de este al futuro, en el segundo no hay movimiento, solo una serie ordenada de acontecimientos y situaciones. Según Jaszczolt, no puede considerarse que el flujo temporal se ajuste estrictamente a la realidad, sino que se trata de la manera en que la mente interpreta que los acontecimientos no se produzcan todos a la vez: estamos ante un tipo interno o psicológico de tiempo, mientras que el tiempo real sería más parecido a la cuerda de tender ropa. Si bien el sentido común nos lleva a concebir el tiempo como un vehículo en movimiento, lo cierto es que los historiadores tienden, por el contrario, a emplearlo como si fuera ese tendedero sobre el que se alinean inmóviles los acontecimientos. Ahora se trataría de saber si ese plus de realidad que esta concepción muestra con respecto a la otra se debe precisamente a que resulta más útil para determinadas formas de conocimiento.

La historia cronológica utiliza la cronología como un soporte inmóvil e inmutable sobre el que se localizan los acontecimientos, que deben ser interpretados desde esa estabilidad. La estabilidad ha sido uno de los elementos consustanciales no solo de la representación visual de occidente desde la implementación de la perspectiva pictórica, sino que ha constituido también la metafísica básica de nuestra construcción del conocimiento hasta los trabajos de Prigogine sobre la flecha del tiempo. En la historiografía esta fijeza se traduce en el concepto de documento, que tiene la misma consistencia que la idea de hecho en la filosofía positivista. Fernand Braudel ya advertía sobre la influencia dañina que el concepto de documento había tenido sobre determinada historiografía: «el descubrimiento masivo del documento ha hecho creer al historiador que en la

2 JASZCZOL, K. M. Representing Time: An Essay on Temporality as Modality. Oxford: Oxford University Press, 2009. p. 2. 
autenticidad documental estaba contenida toda la verdad $\iota^{3}$, decía y para corroborar su tesis se refería a las palabras del historiador Louis Halphen, que poco antes aún afirmaba que «basta con dejarse llevar en cierta manera por los documentos, leídos uno tras otro, tal y como se nos ofrecen, para asistir a la reconstitución automática de la cadena de los hechos» ${ }^{4}$. Para este tipo de historia, el tiempo es una línea fija cuya dirección viene dictada por la cronología de los documentos.

No pretendo discutir aquí cuál de estas concepciones es la verdadera o la más acertada porque me parece que todas pueden serlo, dependiendo de si utilizamos el tiempo para subir a una montaña o para tender la ropa. Quiero decir con esto que, dependiendo de para qué utilicemos el concepto de tiempo, en qué situación lo hagamos intervenir, una metáfora será más útil que la otra y, por lo tanto, no parecerá más acertada y verdadera. Pero quiero dejar claro que mi propuesta no puede considerarse relativista puesto que planteo que las metáforas empleadas no solo iluminan dos concepciones del tiempo -la interna, subjetiva, y la externa, objetiva-, que más que contrapuestas son complementarias, sino que además, al plantear los arquetipos temporales desde el ámbito de la imagen, esas metáforas sitúan el tiempo en el terreno inesperado de lo visual. Y el tiempo visualizado se convierte en una herramienta que nos permite concebir la posibilidad de hacer algo con ella. Tengamos en cuenta que, de la misma manera que una herramienta es de alguna forma equiparable a una imagen que visualiza, como indicó Flusser, un conjunto de ideas, también una imagen puede ser considerada como una herramienta a través de la que se puede actuar, aunque sea con la imaginación. Así como en una herramienta hay ideas latentes, en una imagen hay acciones latentes. Las imágenes del tiempo son, a la vez, la visualización de acciones que el tiempo ejecuta sobre la realidad -primordialmente sobre el espacio pero también sobre los objetos-, y también la visualización de posibles acciones futuras. Es por ello que en gran parte de las imágenes temporales de la actualidad, especialmente aquellas que pertenecen al medio digital, el pasado, el presente y el futuro están unidas por un mismo proceso fluido: forman un conglomerado unitario. Si pensamos en la utilización del plano secuencia por algunos cineastas modernos y contemporáneos,

3 BRAUDEL, Fernand. La historia y las ciencias sociales. Madrid: Alianza Editorial, 1970. p. 66.

4 Ibidem, e HALPHEN, Louis. Introduction à l'Histoire. París: P.U.F., 1946. 
desde Miklós Jancsó a Brian de Palma, Haneke, Angelopoulos o Bela Tarr, comprenderemos mejor las características de estas cápsulas temporales que mediante la duración conjugan visualmente el tiempo.

Pero, antes de seguir avanzando, permítanseme unas palabras más sobre el tan denostado relativismo epistemológico, palabras que creo que son necesarias para evitar que la argumentación se atasque en cuestiones ideológicas. ¿Debemos suponer, por ejemplo, que la concepción del tiempo según la teoría de la relatividad de Einstein era relativista? Creo que la respuesta es no, puesto que precisamente una de las novedades de esta teoría era el hecho de que la relatividad de las mediciones temporales debía ser considerada una condición objetiva del mundo material. Para Husserl, por el contrario, es la mente que crea el tiempo real. Como indica Jaszczolt: «Para (Stephen) Hawking, el tiempo es relativo porque es un elemento del espacio-tiempo (mientras que por el contrario) para Husserl el tiempo solo puede considerarse natural cuando lo contemplamos desde el lugar ventajoso de la vida humana $\rangle^{5}$. Para una de estas concepciones, la relatividad es objetiva; para la otra, la objetividad es relativa.

Estamos todavía secuestrados por la necesidad de encontrar respuestas absolutas a nuestras preguntas, no concebimos otra ciencia que aquella que nos conduce a resultados ciertos e irrefutables, a pesar de que desde el propio campo de la ciencia se reconoce que esta es siempre provisional: que, puesto que no cesa nunca de avanzar, sus resultados jamás pueden considerarse definitivos. Precisamente contra la idea decimonónica de que el examen de los documentos históricos puede acabar por establecer una verdad definitiva de los procesos del pasado, citaba E. H. Carr "The New Cambridge Modern History” en cuya edición de 1957 se indicaba que, de su trabajo, los historiadores «esperan que sea superado una y otra vez. Consideran que el conocimiento del pasado ha llegado a nosotros por mediación de una o más mentes humanas, ha sido "elaborado" por estas, y que no puede, por tanto, consistir en átomos elementales e impersonales que nada puede alterar ${ }^{6}$. De modo que la visión tradicional del tiempo como una línea inmóvil que tenían los historiadores clásicos se convierte, para los modernos, en un flujo al que se van incorporando incesantemente nuevos historiadores y, con ellos, nuevas interpretaciones. ¿Qué sentido tiene, pues, seguir ateniéndose

6 CARR, E. H. ¿Qué es la historia? Barcelona: Seix Barral, 1973. p. 10. 
a las ideas sobre el espacio y el tiempo que Newton consideraba válidas por siempre y en todas partes? No parece que tenga ninguno y no solo porque Einstein las relativizara en su momento, sino porque, entre otras cosas, ahora el tiempo tiene otra dimensión, la dimensión visual.

Mi intención al plantear estas cuestiones no es discutirlas a fondo, sino que con ellas pretendo delimitar correctamente un territorio que les es precisamente ajeno, si bien los elementos fundamentales de este nuevo territorio aparecen en el vacío que aquellas dejan. No se trata, pues, de resolver esas dificultades conceptuales, sino de dejarlas entre paréntesis con el fin de que nos podamos dedicar a lo que realmente nos interesa, a saber: qué tipo de historia se desprende del tiempo visualizado o sea del tiempo en las era de las imágenes.

\section{El tiempo visualizado}

A finales del siglo XIX, científicos, escritores, poetas y pintores descubrieron, cada cual a su manera, esa cuarta dimensión temporal del espacio que Minkowski y Einstein conceptualizarían luego, pero posiblemente nadie en ese momento reparo en una quinta dimensión que se escondía en el tiempo visualizado.

Deleuze, a partir de las ideas de Bergson, planteó una cuestión fundamental que nos libraba de la concepción tradicional del tiempo, ligado al fantasma de la narrativa. Cuando diferenció la imagen-movimiento de la imagen-tiempo, nos situó delante del tiempo visualizado, impidiéndonos confundir el tiempo puro con el tiempo ilusorio que nos proponen los encadenamientos narrativos, las acciones relacionadas a través de las causas y los efectos. Una cosa es, decía, la ilusión temporal que nos transmite un encadenamiento de acciones y la otra el tiempo puro, expresado en sí mismo: el transcurrir experimentado directamente. Deleuze podía hacer esta distinción, no solo porque se apoyaba en las ideas homólogas de Bergson, sino porque pensaba a partir de imágenes cinematográficas, que son la primera instancia a través de la que el tiempo fue visualizado en lo que constituyó, en su momento, una revolución epistemológica transcendental, cuyo alcance solo ahora empezamos a comprender. 
Tenía razón Bergson cuando indicaba que el tiempo no podía dividirse y que, por lo tanto, no podía ser representado por una técnica que tenía como base una fragmentación tan drástica como la que suponían los fotogramas. Pero al parecer se olvidaba de que el dispositivo cinematográfico está escindido en dos mitades, una técnica y la otra fenomenológica, y que la experiencia de la imagen proyectada constituye un salto cualitativo con respecto a la base tecnológica que la hace posible. La primera parte corresponde al paradigma mecánico ya entonces en decadencia, la segunda al paradigma fluido que está naciendo y que en el futuro se consolidará con los procesos de digitalización, para desembocar finalmente en la imagen-interfaz. La experiencia fenomenológica de la película proyectada suministra verdaderas imágenes del tiempo, son tiempo visualizado.

Esta es la primera parte del fenómeno. Aquella por la que el tiempo se materializa, pero el cine, como culminación de los múltiples aparatos que le precedieron en esta tarea, también temporaliza el espacio. En la era de lo que Benjamin denominada la reproductibilidad técnica, es decir, en el momento en que las imágenes se convierten en imágenes técnicas ${ }^{7}$, en el momento en que la tecnología y la formas de representación se hibridan, las imágenes dejan de estas basadas en su condición estática y pasan a ser inestables. Hasta entonces habían sido esencialmente fijas, y ya se sabe, porque es un lugar común, que con el cine van a ponerse en movimiento, ajustándose así a las reglas de una metafísica de carácter teleológico que conduce las imágenes hacia la redención final de su absoluto realismo. Pero, en principio, este movimiento de carácter naturalista no es lo fundamental del nuevo estatus de las imágenes, sino que lo más relevante reside en el hecho de que su materialidad se desvanece y pasan a mostrar una condición fluctuante. Tal como indica Didi-Huberman, refiriéndose a las ideas de Warburg sobre el cuerpo de la imagen renacentista, «como por un movimiento de respiración o como por un ritmo diástole y de sístole, la imagen bate. Oscila hacia el interior y hacia el exterior. Se abre y se cierra» ${ }^{8}$. Pero la imagen técnica experimenta esta pulsión porque la acción del tiempo se introduce en ella por vía de los aparatos, lo que origina su inestabilidad, y este nuevo estado de las imágenes permite una primera visualización de lo

7 FLUSSER, Vilém. Una Filosofia de la fotografia. Madrid: Síntesis, 2001.

8 DIDI-HUBERMAN, Georges. La imagen superviviente. Historia del arte y tiempo de los fantasmas según Aby Warburg. Madrid: Abada, 2009. p. 190. 
temporal. No estoy hablando tanto de duración, como de un cierto temblor que las desestabiliza y constituye una antesala del tiempo propiamente dicho. Es a la vez un anti-movimiento y un pre-tiempo que desnaturaliza tanto al movimiento como al tiempo. Por ello podemos decir que las imágenes cinematográficas, como caso específico y aventajado de las imágenes técnicas, más que un tiempo espacializado o un espacio temporalizado, lo que visualizan es el nuevo concepto de espacio-tiempo, es decir la nueva configuración que planteará un poco más tarde Hermann Minkowski desde el ámbito de la geometría y las matemáticas.

Como decía al principio, a la historia le resulta difícil acomodarse a estas nuevas ideas del tiempo. El imaginario de los historiadores no está generalmente preparado para dar el salto conceptual que se precisa para contemplar temporalmente los objetos que estudia. Pero ello no quiere decir que la presencia de lo temporal no haya influido en alguno de ellos. Pensemos, por ejemplo, en el énfasis que hace Braudel en lo que él denomina la larga duración, en detrimento del tiempo breve y el tiempo mediano, que «no son más que espejismos que han sido producto de nuestra interpretación fugaz de los hechos ${ }^{9}$. La misma concepción de la historia relacionada con el concepto de civilización implica situarse en una perspectiva global que favorece la detección de los flujos a través de los que se agrupan temporalmente los hechos. El primer indicio de que algo estaba cambiando en la sensibilidad del historiador influido por una concepción aún abstracta del tiempo, lo muestra el preclaro diagnóstico que el propio Braudel hace de la historia tradicional:

El pasado está, pues, constituido, en una primera aprehensión, por esta masa de hechos menudos, los unos resplandecientes, los otros oscuros e indefinidamente repetidos; precisamente aquellos hechos con los que la microsociología o la sociometría forman en la actualidad su botín cotidiano (también existe una microhistoria). Pero esta masa lo constituye toda la realidad, todo el espesor de la historia, sobre el que la reflexión científica puede trabajar a sus anchas. La ciencia social casi tiene horror

9 BARRAGÁN ABREU, Oscar J. Fernand Braudel: Limitaciones ontológicas de sus categorizaciones históricas. Procesos Históricos, Universidad de Los Andes, año 7, n. 13, p. 119, Primer Semestre 2008. 
del acontecimiento. No sin razón: el tiempo corto es la más caprichosa, la más engañosa de las duraciones. ${ }^{10}$

Esta apreciación era compartida por un historiador de corte muy distinto, a pesar de que participaba con Braudel del interés por el concepto de civilización: Arnold Toynbee. Sigfried Kracauer se refiere a sus ideas con una cierta suspicacia: «Toynbee, cuyo "campo de estudio inteligible" -las civilizaciones en su globalidad-solo se hace visible a una enorme distancia de (donde se encuentran) las evidencias, habla, no sin condescendencia, del historiador "miope" que, escarbando muy por debajo, ignora las vistas de las que él disfruta»" ${ }^{11}$. Más adelante, el mismo Kracauer se referirá al concepto de tiempo histórico de Spengler:

\begin{abstract}
¿Cómo nos debemos imaginar, se pregunta, el medio temporal común en el que las culturas spenglerianas con su tiempo peculiar emergen, se desarrollan y perecen? Si consideramos que Spengler admite que existen transiciones entre ellas, se encuentran sumergidas en el flujo del tiempo cronológico que de esta manera se ve reactivado; pero cuando insiste en la completa autonomía de estas culturas, el medio temporal común se convierte en un especie de vacío cultural, una impensable contrapartida de la eternidad. ${ }^{12}$
\end{abstract}

No está de más señalar que este vacío temporal que alberga las distintas temporalidades culturales según Spengler, y que Kracauer considera impensable, se corresponde perfectamente al lugar donde David Wark Griffith en su famosa película "Intolerancia" (Intolerance, 1916) hace aparecer el conjunto de las cuatro temporalidades históricas entrelazadas que la forman: Babilonia, La pasión de Cristo, la matanza de los Hugonotes (Francia, S. $\mathrm{XVI}$ ), la actualidad (USA, principios del siglo XX). Ese lugar que, a modo de contenedor, asume la interacción de estas distintas franjas temporales no es otro, pues, que el propio espacio del film, que se hace aparente a través de la acción de las diversas temporalidades. Es en él donde se visualiza esa

10 BRAUDEL, Fernand. Op. cit., p. 66.

11 KRACAUER, Sigfried. History. The Last Things before the Last. Princeton: Markus Wiener Publishers, 1969. p. 105.

12 Ibídem, p. 141. 
contrapartida de la eternidad de la que habla Kracauer y que también vemos reproducida en una película más reciente y de similar estructura: "Cloud Atlas: la red invisible" (Cloud Atlas, 2012) de Anda y Lana Wachowski.

Este tipo de películas, que no abundan demasiado, ${ }^{13}$ nos muestran una temporalidad global que no corresponde al tiempo cronológico, sino a un tiempo absoluto y, por ello, se hallan fuera del tiempo en sí: una región meta-temporal capaz de acoger en su seno otras temporalidades. Tampoco puede decirse que se trate de un espacio propiamente dicho. En todo caso es un espacio configurado por el tiempo: son las distintas temporalidades entrelazadas las que dan forma a este peculiar espacio formado por un tejido de tiempos.

Hay que señalar, no obstante, que esta meta-temporalidad no es equivalente a la estática cuerda de tender la ropa antes mencionada, sino que corresponde en realidad a un tiempo total que cambia constantemente, a medida que las distintas temporalidades que la forman se suceden y superponen unas a otras. Se trata, pues, de un tiempo-espacio que está formado por una suma dialéctica de tiempos. Es decir que no es otra cosa que la antesala del espacio-tiempo.

Bergson llega a la conclusión de que el sentido común nos lleva a pensar en un tiempo impersonal que contendría todas las cosas, ya que es posible imaginar que el entorno que cada uno de nosotros percibe está en contacto con el de los demás y participa, por tanto, de las mismas experiencias, por lo que se podría establecer así una cadena de contactos que cubriría todo el universo: «se trata de consciencias múltiples, surgidas de la nuestra, parecidas a la nuestra, a las que encargamos de hacer la cadena a través de la inmensidad del universo y de testimoniar, por la identidad de sus duraciones internas y la contigüidad de sus experiencias externas, la unidad de un Tiempo impersonal» ${ }^{14}$. Pero la conclusión a la que llega

13 "Las horas" de Stephen Daldry (The Hours, 2002) podría ser otra de ellas y el hecho de que la distancia temporal entre las distintas historias no sea en este caso tanta como en los filmes citados no es especialmente relevante. Lo sería solo en el caso de que la temporalidad de los diferentes relatos fuera la misma, configurando un tipo de montaje paralelo, como ocurre en "Shortcuts" (1993) de Robert Altman o en "Magnolia" (1999) de Paul Thomas Anderson. En películas que están compuestas por distintas visiones de un distinto suceso, como "Citizen Kane" (1941) de Orson Welles, "The Bad and the Beautifull" (1952) de Vincente Minnelli o "All About Eve” (1950) y “The Barefoot Contessa” (1954) de Joseph L. Mankiewicz, a lo que asistimos es a una combinación de distintos espacios-percepción dentro de una misma temporalidad. 14 BERGSON, Henri. Durée et simultaneité. París: Presses Universitaires de France, 1992. p. 45 . 
Bergson no deja de resultar sorprendente, ya que según él, «no se puede hablar de una realidad que dura sin introducirle la conciencia» ${ }^{15}$. La experiencia cinematográfica nos conduce a una conclusión parecida, y no solo en el tipo de películas mega-temporales mencionadas, sino que en cualquier película, aunque la trama se desarrolle a través de una típica línea cronológica, se puede detectar un tiempo general que contiene a todos los demás parcialmente mostrados: un tiempo que, en principio, requiere de la conciencia del espectador para manifestarse. Pero digo que esto sucede solo en principio porque además se trata de un fenómeno objetivado por la base tecnológica de la película, por la continuidad de sus fotogramas que constituyen una línea temporal contenedora de distintas duraciones, distintos ritmos y aunque no siempre de distintas temporalidades, sí por lo menos de distintas franjas de una misma temporalidad.

El cine, observado desde esta perspectiva, no haría sino actualizar la concepción de la cultura que propugnaba el antropólogo Edward Tylor, a finales del siglo XIX, un momento de profunda transformación de la idea clásica del tiempo cronológico: «Tylor habría descubierto la extrema variedad, la vertiginosa complejidad de los hechos de cultura [...]; pero también habría descubierto algo aún más perturbador [...]: el juego vertiginoso del tiempo en el interior de la actualidad, en la "superficie" presente de una cultura determinada» ${ }^{16}$.

El rechazo de la historia mecanicista basada en la ordenación cronológica de los hechos y los datos plantea la posibilidad de una visión global, capaz de contemplar grandes ciclos y que, por lo tanto, está a un paso de formalizarlos. Este paso lo da Georges Kubler al proponer su historia de las cosas como «un intento de reunir objetos e ideas bajo la rúbrica de formas visuales $\rangle^{17}$. Obsérvese que Kubler, al titular su estudio La forma del tiempo, nos está indicando que no observa la forma estricta de los objetos contemplados aisladamente, sino la forma fluida que reúne a una serie de los mismos, una morfología que se convierte en la forma del tiempo o en una de las formas posibles del tiempo. Podemos decir, por lo tanto, que el tiempo se puede visualizar a través de la transformación que los objetos

15 Idem.

16 DIDI-HUBERMAN, Georges. Op. cit., p. 55.

17 KUBLER, George. The Shape of Time. Remark on the History of Things. New Heaven y Londres: Yale University Press, 1962. p. 8. 
experimentan al someterse a su transcurrir, o sea, al participar del flujo temporal, siempre que estas transformaciones se contemplen como un conjunto cambiante de formas fluidas. Algo que solo el cine o las formas cinemáticas pueden representar debidamente porque esos dispositivos permiten delimitar meta-temporalidades como las que acabo de indicar. Cuando estas meta-temporalidades se ponen en movimiento, se convierten imágenes fluidas, en tiempo visualizado.

Para decirlo de manera más precisa: el tiempo se visualiza a través de las imágenes fluidas de la realidad cuando estas componen un conjunto visible, no solo imaginable. Obsérvese que estamos hablando de la aparición de un espacio fluido que aglutina diversos elementos. En el caso que plantea Kubler, proviene de un encadenado de formas, y en el de las películas mencionadas, de un encadenado de tiempos. Ambos espacios se asemejan en que dependen de manifestaciones temporales cuya presencia los desmaterializa, los convierte en evanescente, aunque en cada caso de manera distinta. Ambos son también visibles o evidenciables. ¿Dónde se encuentran los límites de una secuencia formal? se pregunta Kubler, y responde: «puesto que la historia es un asunto no finalizado, los límites de sus divisiones se mueven constantemente, y se continuarán moviendo mientras los hombres hagan historia» ${ }^{18}$. Tanto la pregunta como la respuesta ponen de manifiesto que Kubler está pensando en una visualización muy clara de la historia convertida en tiempo formalizado.

Una vez los acontecimientos se reúnen por una afinidad temática, formal o cronológica, se produce una tensión conceptual que debe ser resuelta. La respuesta tradicional a esta tensión suele ser de dos tipos o, mejor dicho, se plantea según dos coordenadas epistemológicas contrapuestas: o se busca una explicación causal o se recurre a una explicación casual. Se considera que la relación es cierta porque tiene una causa o, si no, es que se trata de una casualidad. Pero este doble planteamiento antitético excluye otra posibilidad que, apelando a la idea de Bruno Latour, podríamos denominar facticia ${ }^{19}$. Es decir, algo que es a la vez un hecho y una invención, el resultado conjunto de una causalidad y de una casualidad. Solo que la casualidad es en estos casos significativa, proviene no tanto de un encuentro

18 Ibidem, p. 31.

19 LATOUR, Bruno. Petite réflexion sur le culte moderne des dieux Faitiches. París: Département Communication Synthélabo, 1996. 
fortuito como de una analogía que desvela su pregnancia tras el velo de una aparente eventualidad. Los escritores están trabajando constantemente en el ámbito de lo facticio: su imaginación les lleva a plantear situaciones aparentemente aleatorias que, de inmediato al ser propuestas, revelan un significado más intenso que se convierte en motor de la escritura. Latour estudia en el terreno de la antropología unas formaciones a las que da el nombre de "faitiches", neologismo compuesto de la palabra fait, en francés hecho, y fetiche: es decir, hechos-fetiches: «ahora podemos escoger entre dos repertorios: aquel en el que se nos ordena a escoger entre construcción y verdad, y aquel otro en el que construcción y realidad se convierten en sinónimos» ${ }^{20}$. Las formaciones históricas que se basan en una estructuración espacio-temporal de los fenómenos tienen esta particularidad.

\section{Movimiento, fluctuación y fantasmagoría}

Como decía antes, el movimiento no es esencial en una primera aproximación a las nuevas imágenes que inaugura la técnica cinematográfica, y, por lo tanto, no debe contemplarse como el detonador del cambio que conduce al nuevo paradigma. Más determinante es la inestabilidad, que aparece no solo en las imágenes en movimiento, sino también en algunas de las que, siendo de la misma época transitoria, aún pertenecen al paradigma de las imágenes fijas. Recordemos los experimentos fotográficos de Marey y Mulvey, cada uno de los cuales expresa a su manera esa vacilación visual que también encontramos en las pinturas futuristas de Marinetti y Carlo Carrà, en las esculturas de Umberto Boccioni o en la fotografías de Anton y Arturo Bragaglia, por citar solo alguno de los casos más destacados del período. Aunque quizá sea "Desnudo bajando una escalera" de Duchamp la pieza fundamental para comprender esa primera forma de inestabilidad que se da en las imágenes aún inmóviles, nos podríamos fácilmente remontar a cien años antes y hablar de las primeras narraciones gráficas de un dibujante tan innovador como Rodolphe Toppfer que, a principios del siglo XIX, no solo anunciaba la estructura típica del cómic, sino que al mismo tiempo

Ibídem, p. 47. 
confeccionaba algunas viñetas que podríamos calificar de fluctuantes o vacilantes. Toppfer, al pretender mostrar visualmente el movimiento, la duración, creaban imágenes inestables e indeterminadas que eran prácticamente las primeras de su tipo. Como constatan Umberto Eco y Omar Calabrese en un libro conjunto sobre el tiempo en pintura, es cierto que en la representación prerrenacentista ya existe una tendencia a explicar las historias mediante el equivalente de las viñetas de un cómic por medio de las que se escenificaba la acción ${ }^{21}$. Pero debemos tener en cuenta algo fundamental que diferencia los paneles de la pintura prerrenacentista de los planteamiento de Toppfer (puede que las discrepancias no estén tan claras en el caso de las viñetas del cómic clásico), a saber que el dibujante suizo no escenifica tiempos aislados, sino que pretende representar la duración mediante artilugios retóricos de carácter visual que desestabilizan la representación, algo que no ocurre ni en la pintura ni en el cómic más clásico.

Al plantear la importancia de la desmaterialización de la imagen que se produce sobre todo a partir de la segunda mitad del siglo XIX, no debemos olvidar el peculiar estilo de una figura como Victor Hugo, no solo en su faceta de escritor en la que ya se detectaba una cierta sensibilidad por las imágenes indeterminadas, sino principalmente en un aspecto menos conocido de su obra, los dibujos. Riffaterre califica la técnica poética de Hugo como de un «devenir dinámico». Se trata de «el paso de una forma a otra, la disolución de las formas. Así la evocación de un hombre absorbido, asimilado por una hidra, recuerda la descomposición de Mr. Valdemar en el cuento de Edgar Allan Poe [...] se trata de una estética especial creada ad hoc, la estética de la metamorfosis» ${ }^{22}$. Este proceso de metamorfosis se detecta también, como digo, en los dibujos del escritor, donde las formas se diluyen, pierden solidez, y muestran una faceta onírica de formas fluctuantes, todo ello sin abandonar el ámbito de las imágenes fijas que son sus dibujos. Tanto los escritos como los dibujos de Hugo responden a un mismo tipo de imaginación que se caracteriza por intuir un fenómeno tan moderno con es ese devenir dinámico del que habla Riffaterre. Baste recordar el famoso capítulo de "El jorobado de Notre-Dame", titulado "Ceci tuerá cela" (Esto

p. 21.

p. 281 .
21 ECO, Umberto; CALABRESE, Omar. El tiempo en la pintura. Madrid: Mondadori, 1987.

22 RIFFATERRE, Michael. Ensayos de estilística estructural. Barcelona: Seix Barral, 1976. 
matará aquello), cuya estructura expositiva constituye un perfecto ejemplo de la imaginación fluida del escritor. En este capítulo se describe, a través de un vertiginoso flujo temporal, la evolución simbólica de la arquitectura en relación con la escritura.

Pero la verdadera importancia del movimiento se manifiesta en el interior del nuevo régimen de las imágenes efectivamente inestables $\mathrm{y}$, por lo tanto, no podemos comprenderla de manera adecuada si no hemos entendido lo que esta nueva formación, o deformación, de las imágenes significa en la historia de la representación visual. Solo una vez que hayamos dado este paso podremos observar que el movimiento aparece como la esencia del tiempo, ya que se mostrará como factor de transformación y no como aditamento naturalista que soluciona una pretendida carencia de las imágenes fijas.

No deja de ser curioso que Deleuze, ignore en su libro sobre la imagen-tiempo el concepto de imagen dialéctica de Benjamin cuando tan cercano se encuentra del de imagen-cristal que se describe en este texto. Y no será porque Deleuze desconozca los escritos del pensador alemán, al que se refiere en un par de ocasiones en el libro. En todo caso, existe una perfecta resonancia entre ambas concepciones referidas las dos a la superposición de tiempos. Para Deleuze, la imagen cristal es como un espejo donde se refleja la condición misma de la imagen, es decir, una representación en la que coinciden lo real y lo imaginario a través de un juego de reflejos. El propio Deleuze lo dice más concretamente: «Así pues, la indiscernibilidad de lo real y lo imaginario, o de lo presente y lo pasado, lo actual y lo virtual, no se produce de ninguna manera en la cabeza o en el espíritu sino que constituye el carácter objetivo de ciertas imágenes existentes, dobles por naturaleza» ${ }^{23}$. Según Agamben, la imagen es dialéctica cuando se encuentra en situación de suspensión, y él mismo aclara que el término original Stillstand «no indica simplemente una detención, sino un umbral entre la inmovilidad y el movimiento» ${ }^{24}$, es decir, ni más ni menos que la condición que empiezan a tener las imágenes técnicas a finales del siglo XIX, que es precisamente el mismo período en el que Benjamin detectará más tarde esta condición en su estudio sobre los pasajes parisinos.

99.

23 DELEUZE, Gilles. La imagen-tiempo. Estudios sobre cine 2. Barcelona: Paidós, 1987. p.

24 AGAMBEN, Giorgio. Ninfas. Valencia: Pre-Textos, 2007. p. 30. 
Cuando Didi-Huberman sitúa las nuevas concepciones de Warburg en lo que denomina tiempo de los fantasmas ${ }^{25}$, está pensando en estas nuevas imágenes que han perdido su estabilidad y se muestran a través de su fantasmagórica disolución. Pero recordemos, antes de llegar a este punto crucial, que Deleuze, en sus análisis de la filosofía de Bergson, establece una ecuación transcendental entre materia, movimiento e imagen: «nos dice (Bergson) que el verdadero movimiento es la materia y la materia-movimiento es la imagen $\rangle^{26}$. La materia se encuentra, pues, según Bergson, en constante movimiento y el resultado de este movimiento es la imagen. Con ello descubrimos hasta qué punto la forma fundamental de las imágenes clásicas se aleja, en su proverbial condición estática, de la propia realidad que quería representar fidedignamente, puesto que esta realidad no es más que constante movimiento que produce imágenes: imágenes que surgen pues de movimiento y que han de ser básicamente fluctuantes. Sin embargo ello no quiere decir que la distancia epistemológica y estética se resuelva con el recurso al movimiento naturalista del cine, sino que hay que profundizar más para encontrar el verdadero sustrato de las nuevas imágenes, aquel que cataliza su condición inestable.

«Siendo el universo, según afirma Deleuze, el conjunto de las imágenes-movimiento en tanto accionan y reaccionan unas con otras» ${ }^{27}$, cualquier corte aplicado a ese movimiento general es ilusorio: no debe confundirse, añade, «el corte inmóvil del movimiento con el movimiento mismo como corte de la duración ${ }^{28}$. El enunciado parece confuso pero no lo es tanto: en realidad lo que está diciendo Deleuze, al interpretar a Bergson, es algo ya conocido de las tesis de este. A saber, que el tiempo no puede surgir de cortes inmóviles, de ahí que Deleuze en sus estudios sobre el cine hubiera llegado a la conclusión de que existe una diferencia sustancial entre las imágenes-movimiento y las imágenes-tiempo.

Uno de los ejemplos que ofrece Deleuze para comprender el asunto de los cortes del movimiento se refiere a la imagen del átomo. Con ello ilustra claramente la diferencia de potencial epistemológico entre las imágenes pertenecientes al paradigma de la inmovilidad y las imágenes móviles. Del

p. 153.

26 DELEUZE, Gilles. Cine I. Bergson y las imágenes. Buenos Aires: Editorial Cactus, 2009.

27 Ibidem, p. 152.

28 Idem. 
planteamiento de Deleuze, se desprende que si la materia es movimiento constante, también han de estar en incesante movimiento los átomos que la forman: en realidad, la materia debe ser considerada la imagen que resulta del movimiento atómico. Por lo tanto, la imagen tradicional del átomo, tanto la que ha sido representada mediante ilustraciones como la imagen mental del mismo que nos hemos formado, implicarían la existencia de un «típico corte inmóvil operado sobre el movimiento [...] el átomo es siempre inseparable de un flujo, de una onda, de una onda de acción que recibe y de una onda de reacción que emite ${ }^{29}$. Es verdad que estas concepciones del átomo pueden ser consideradas metafóricas, pero no es menos cierto es que de ellas se han derivado importantes conclusiones científicas.

El problema no concierne tan solo a la física o a la filosofía, sino que tiene que ver, de forma muy directa, con los sistemas de representación, puesto que pone de manifiesto hasta qué punto la realidad representada estáticamente promueve una visión engañosa de la misma y, por lo tanto, no solo distorsiona el conocimiento, sino que le impide avanzar. Se trata de un asunto que viene de lejos y es más delicado de lo que parece. Este típico corte inmóvil sobre el movimiento es sustancial a nuestra forma de entender la realidad y por consiguiente de representarla. Pensamos aún a partir de imágenes inmóviles, quizá porque todavía estamos bajo el influjo de Platón y consideramos que solo de este tipo de imágenes se puede desprender un conocimiento verdadero. Para el filósofo solo las Ideas son verdaderas porque son fijas e inmutables, es decir, porque carecen de tiempo.

Panofsky consideraba que la perspectiva pictórica era una forma simbólica y que, por lo tanto, produce imágenes ideales y no reales. Es a partir de este tipo de imágenes que organizamos nuestro conocimiento. Cuando Belting comenta estos planteamientos, añade que: «nuestra mirada ve cuerpos y espacios, pero la perspectiva la simboliza bidimensionalmente y para ello utiliza la pantalla como símbolo. El espacio está allí porque es utilizado como espacio de la mirada. La pantalla de la perspectiva es una metáfora de la presencia de un espectador construido solo como función de la imagen ${ }^{30}$. Como sea que la realidad, desde las partículas atómicas hasta la mirada del sujeto que observa el mundo a su alrededor, es una

29 Idem.

30 BELTING, Hans. Florencia y Bagdad. Una historia de la mirada entre Oriente y Occidente. Madrid: Akal, 2012. p. 19. 
imagen en constante movimiento, apostar por la inmovilidad como hizo la representación perspectivista hasta la llegada del cine e incluso más allá, y como hace en general la epistemología clásica, es plantearse un mundo ideal en el que el tiempo apenas si tiene cabida, si no es como una construcción subjetiva y poco funcional.

Como ya he dicho, de este atasco no se sale a través del análisis superficial del movimiento naturalista de las imágenes cinematográficas, sino que solo el tiempo visualizado pone de manifiesto tanto las contradicciones de las representaciones estáticas, como las de las imágenes que reproducen miméticamente el movimiento superficial de las cosas. Tan solo cuando reparamos en que el cine materializa, visualizándolo, el espacio-tiempo podemos dejar atrás estos malentendidos y penetrar en la esencia de las nuevas formas de representación. El cine pone en movimiento las Ideas y formaliza su transformación, que se convierte así en tiempo visual.

\section{El espacio-tiempo}

La atención sobre los modernos cambios en la concepción de la naturaleza del tiempo se ha concentrado casi siempre en Einstein, olvidando a veces las aportaciones fundamentales que sobre el fenómeno hizo Minkowski, mucho más radicales en algunos sentidos. Él fue el creador del concepto de espacio-tiempo, que constituye la verdadera revolución no solo de la nueva física, sino también de la nueva concepción de la realidad que la misma acarrea. Minkowski, algo raro en un matemático, defendía que el espacio-tiempo correspondía a una realidad objetiva de cuatro dimensiones y que, por lo tanto, no se trataba solo de una conveniente representación de los planteamientos de la teoría de la relatividad ${ }^{31}$. Al principio de su célebre conferencia sobre las relaciones entre el espacio y el tiempo, Minkowski afirmaba contundentemente que «de ahí en adelante el espacio por sí mismo y el tiempo por sí mismo están condenados a convertirse en meras

31 PETKOV, Vasselin (Ed.). Minkowski Spacetime: A Hundred Years Later. Londres y Nueva York: Springer, 2010. p. V. 
sombras, y solo una suerte de unión entre los dos conservará una realidad independiente $\aleph^{32}$.

El espacio tiempo significa en sí mismo una superación de la cuarta dimensión temporal, la duración, que se ha añadido tradicionalmente a las otras tres dimensiones espaciales. No se trata tan solo de que el mundo material (nuestra percepción del mismo, diría Bergson) deba tener una duración para poder realmente existir (o ser percibido, memorizado), es decir, no se trata solo de que el espacio se asiente en el tiempo, sino que el tiempo forma parte consustancial del espacio, ambos constituyen la urdimbre inseparable del mundo material.

Pero debemos conceder que existe aún otra dimensión que se añade a estas cuatro y al conglomerado espacio-temporal que todas ellas configuran: se trata de la dimensión visual. El tiempo y el espacio son categorías no esencialmente visibles, puesto que del espacio vemos su emanación a través de la relación entre las cosas, y al tiempo lo observamos también indirectamente por la duración de esas mismas cosas. El espacio-tiempo tampoco es perceptible en sí mismo, aunque su existencia genera resultados fenoménicos. Pero en el momento en que, mediante el concurso de la tecnología, se genera no solamente una representación, sino incluso una genuina presentación del espacio-tiempo, esta faceta de lo real se convierte en una plataforma activa dispuesta a ser utilizada estética y experimentalmente. Este uso no forma parte intrínseca de la fenomenología del espacio-tiempo en sí mismo, sino que es una nueva dimensión que amplía su esencia, desplaza las cuatro dimensiones de lo real hacia otro ámbito ligado directamente con el conocimiento de esa parcela de la realidad, a la que sobrepasa.

El espacio-tiempo visualizado, ya sea a través del cine -por ejemplo en los planos secuencia- o mediante las nuevas imágenes interfaz, se convierte en una herramienta que puede ser catalogada de mental. Antes hemos podido observar cómo Bergson planteaba que la percepción del tiempo implica la introducción de la conciencia en la concepción del mismo, puesto que solo mediante la imaginación y la memoria puede realmente existir este tiempo de carácter universal o impersonal que supuestamente demanda el sentido común. Pero olvidémonos ahora de la discusión sobre si es o no posible este tipo de tiempo y conservemos de esta hipótesis tan solo

32 MINKOWSKI, Hermann. Space and Time, en Vesselin Petkov (Ed.). Minkowski Spacetime: A Hundred Years Later. Londres y Nueva York: Springer, 2010. p. XV. 
aquellas consecuencias que sean útiles, especialmente la que se refiere a la necesaria participación de la conciencia en la concepción de la temporalidad, idea que una vez detectada genera una serie de reflexiones cuyo potencial ya no depende de la veracidad de la hipótesis originaria.

Si existe una coalición indiscernible entre el tiempo y la conciencia, una amalgama que forma la base de lo real, esta fusión debe corresponder también al entramado del espacio-tiempo. Pero este desplazamiento solo puede concebirse a través de la visualización de la alianza, puesto que si bien las consecuencias del tiempo y el espacio son asequibles directamente, no así las del espacio-tiempo, que solo pueden ser imaginadas y, en todo caso, simbolizadas matemáticamente como ocurre con la mayoría de los fenómenos de la física cuántica. Precisamente esta circunstancia ya originó en su momento una serie de trascendentales discusiones en el seno de esta disciplina entre los partidarios y los contrarios de la visualización o del realismo de los fenómenos que se derivan de sus postulados.

Según Agamben, «la imaginación circunscribe un espacio en el que no pensamos todavía, donde el pensamiento se hace posible a través de la imposibilidad de pensar» ${ }^{33}$. La imagen es el instrumento que hace posible pensar en ese espacio en el que ante no era posible hacerlo. Warburg fue capaz de imaginar, a través de los paneles de su "Atlas Mnemosyne", el flujo temporal que une las imágenes de distintas épocas. Esos paneles eran espacios meta-temporales que agrupaban las distintas temporalidades de las imágenes que contenían y que además permitían detectar, también imaginativamente, el flujo formal y temporal que las unía. Warburg, con esta operación, se quedaba solo a un paso de visualizar el espacio-tiempo. Para ello le faltaba únicamente el movimiento. Un movimiento que hubiera sido esencialmente temporal.

El cine ya contenía la esencia de este movimiento relacionado con el pensar, pero del mismo no surgió una efectiva herramienta epistemológica hasta que la imagen digital permitió que fuera verdaderamente práctica. Atrás quedaba las experiencias realizadas con el plano secuencia por algunos cineastas memorables, capaces de pensar al margen de las limitaciones que André Bazin le ponía a esta forma retórica, así como también quedaban atrás algunos experimentos de las vanguardias con el ralentizado o el ace- 
lerado de las imágenes, acciones capaces de hacer visible lo que no lo era por el ojo humano directamente, tal como indicaba a Benjamin al hablar del inconsciente óptico. De todos ellos, quizá fue Jean Epstein el que mejor comprendió las relaciones del cine con la fenomenología espacio-temporal:

En la representación cinematográfica, el movimiento parece inherente a la forma; es y hace la forma. Por ello un nuevo empirismo -el del instrumento cinematográfico- exige la fusión de dos nociones primeras: la de la forma y la del movimiento. El cinematógrafo no adquiere la forma más que por la forma de un movimiento. ${ }^{34}$

El espacio tiempo aparece visualizado, de forma abstracta, en las series fractales en movimiento, y en concreto en algunos de los videos de Bill Viola, especialmente los agrupados bajo el título de "The Passions", donde los cuerpos de los actores que reproducen las poses prototípica de la pintura clásica, y por tanto ligadas a la inmovilidad, se ponen en movimiento, aunque lo hacen tan lentamente que ese movimiento ralentizado expresa más la temporalidad del gesto que su movimiento propiamente dicho.

Pero debemos llegar al concepto de imagen-interfaz, la imagen fluida por excelencia, para que la herramienta mental que implica el espacio-tiempo de cinco dimensiones, sea realmente efectiva. La interfaz es, a grandes rasgos, la zona visual que comunica el ordenador con el usuario o, más concretamente, la tecnología con el ser humano. Zona intersticial por excelencia a través de la que se conjugan la acción y el pensamiento, visualizados ambos mediante flujos metafóricos que abren constantemente nuevos ámbitos de acción-creación. El famoso flujo de la conciencia descrito por William James en el siglo XIX, y actualizado por escritores como Joyce en el XX, se convierte en una herramienta mental-visual en el XXI.

Las nociones apriorísticas de Kant se convierten así en espacios de enunciación, en plataformas para pensar el mundo visualmente. Tiempo y espacio que, según Kant, eran categorías básicas de estructuración del mundo humano que delimitan lo real posible, se superponen ahora a esta

34 Citado por: DUBOIS, Philippe. "La Tempête et la matière-temps ou le sublime et le figural dans l'œuvre de Jean Epstein”, en Jacques Aumont (Ed.). Jean Epstein. Cinéaste, poète, philosophe. París: Cinématheque Française, 1998., p. 283. 
realidad para comprenderla desde otra dimensión. Al desplegarse de esta manera las categorías fundamentales de la ontología de la realidad, se abren las entrañas de la misma y queda así expuesta a una visión sobre-humana su composición básica, formada por un conjunto inextricable de lo real y lo imaginario.

Recebido em: 06/04/2014. Aprovado em: 10/06/2014. 